International Journal of Engineering \& Technology, 7 (4.20) (2018) 321-324
International Journal of Engineering \& Technology
SPC
Website: www.sciencepubco.com/index.php/IJET
Research paper

\title{
Enhancement of Subgrade Properties Using Magnesium Oxide for Pavement Construction
}

\author{
${ }^{1}$ Lubna A. Salem, ${ }^{2}$ Amer Hasan Taher, ${ }^{3}$ Ahmed Mancy Mosa* \\ ${ }^{I}$ Civil Engineering Department, AL Mansour University College, Baghdad, Iraq \\ ${ }^{2}$ Civil Engineering Department, College of Engineering, Al-Mustansiriah University, Baghdad, Iraq \\ ${ }^{3}$ Civil Engineering Department, AL Mansour University College, Baghdad, Iraq \\ *Corresponding authorE-mail: ahmed.mancy@muc.edu.iq
}

\begin{abstract}
This study aims to use Magnesium Oxide $(\mathrm{MgO})$ as one of the modern additives to improve the properties of subgrade and consequently improve the pavements system structure and durability as well as reducing the cost of construction and maintenance of the constructed pavements. The study adopted California Bearing Ratio (CBR) testing method and cyclic triaxial compression test (this test is used to determine the soil resilient modulus (Mr)) to investigate the influence of $\mathrm{MgO}$ on the properties of a selected soil obtained from Baghdad city. Six doses $(0.25 \%, 0.5 \%, 0.75 \%, 1 \%, 1.25 \%$, and $1.5 \%$ of the dry weight of soil) of $\mathrm{MgO}$ were added to the selected soil to attain the objective of this study. The results exhibited that CBR values increased from $3.39 \%$ to $(13.59 \%, 18.45 \%, 27.54 \%, 25.24 \%, 16.99 \%$, and $14.56 \%$ ) respectively, the $\mathrm{Mr}$ values increased from $35 \mathrm{MPa}$ to $(83,97,150,137,110$ and $103 \mathrm{MPa})$ respectively and the swelling ratios decreased from $3.4 \%$ to $(1.51 \%, 0.80 \%, 0.61 \%, 0.66 \%, 1.18 \%$, and $1.97 \%)$ respectively by adding $\mathrm{MgO}$ doses, previously, mentioned. Based on these results the optimum $\mathrm{MgO}$ dose is $(0.75 \%$ by the dry weight of soil) as it satisfies the highest CBR and Mr values and the lowest swelling ratio.
\end{abstract}

Keywords: $C B R, M g O$, properties enhancement, resilient modulus, subgrade

\section{Introduction}

Efficient transportation is essential for economy growth in any country [1] especially in developing countries [2]. Among the transportation facilities such as airports, marinas, and railways, highways can be considered as the main facility [3]. Highway involved several components such as lanes, medians, shoulders and others [4]; among these, the paved lanes are the major components [5]. The lanes can be paved with rigid or flexible pavements [6, 7]. In both cases, the pavement layers are constructed on subgrade [8]. Subgrade can be in situ or borrowed materiel [9]. It represents the foundation of the pavements system [10]. It controls the structural features of the designed pavements layers [11, 12]. Construction of pavement layers on subgrade with excellent to good properties reduces the thickness of the layers and consequently reduces the initial and maintenance cost of the transportation facilities (highways and airport runways) [13, 14]. On the other hand, construction of pavement on poor subgrade class such as A-7 (according to the classification of the American Association of State Highways and Transportation Officials (AASHTO)) which is susceptible to volume change with variation in water content is undesirable [15]. Moreover, soils that has high ability to hold water leads to problems of swelling in subgrade which is one of the most sources of damages in pavements structure. However, construction of pavements on poor subgrade especially under full saturation condition [16] cannot be avoided in several cases $[17,18]$ due to constrain of location, soil properties, environmental effects, and other affecting conditions [19]. Therefore, improvement of subgrade properties is an essential objective $[20,21]$ to obtain strong and durable pavements with least initial and maintenance costs. Improvement is performed, mostly, by stabilization of subgrade using traditional additives such as lime, Portland cement, cement kiln dust, fly ash, and liquid asphalts. Therefore, adoption of new additives in this domain is a revolutionary action. This study aims to improve the properties of subgrade using Magnesium Oxide ( $\mathrm{MgO})$. $\mathrm{MgO}$ is used as an improving additive in Portland cement and concrete technology [22-26]. However, no such research was performed in the domain of subgrade improvement using $\mathrm{MgO}$, to the best knowledge of authors, which leaves a remarkable gap in this domain. To fill this gap, this study starts an important step by adoption of California Bearing Ratio testing method and cyclic triaxial compression test to investigate the effects of $\mathrm{MgO}$ on the properties of soil obtained from Baghdad city. The study involves a series of laboratory tests to attain the objectives. Firstly, the soil was classified based on AASHTO method. Secondly, the optimum moisture content and the maximum dry density were determined for the selected soil. Thirdly, the effects of addition of different doses $(0.25,0.5 \%, 0.75 \%, 1 \%, 1.25 \%$, and $1.5 \%$ of the dry weight of soil) of $\mathrm{MgO}$ were studied using the mentioned tests.

\section{Materials and methods}

\subsection{Soil used proprieties}

Basically, this work is a laboratory oriented investigation. The soil used in this study was obtained from Al-Ghadeer quarter, Baghdad, Iraq. Generally, it is brown soft silty clay. The consistency and other 
physical properties of the soil were studied by a series of tests including classification tests and compaction characteristics as described in the following subsections.

\subsubsection{Grain size distribution}

To determine the grain size distribution of the soil used, wet sieving (by water) and test for materials finer than $75 \mu \mathrm{m}$ (No. 200) sieve in mineral aggregates using hydrometer were performed according to AASHTO T-11 and AASHTO T-27. The grain size distribution curve of the soil sample is shown in Figure 1. Tests exhibited that the percentage of particles less than grain size $75 \mu \mathrm{m}$ (passing sieve No. 200) is $99 \%$ and the percentage of particles with grain size less than $2 \mu \mathrm{m}$ is $12 \%$.

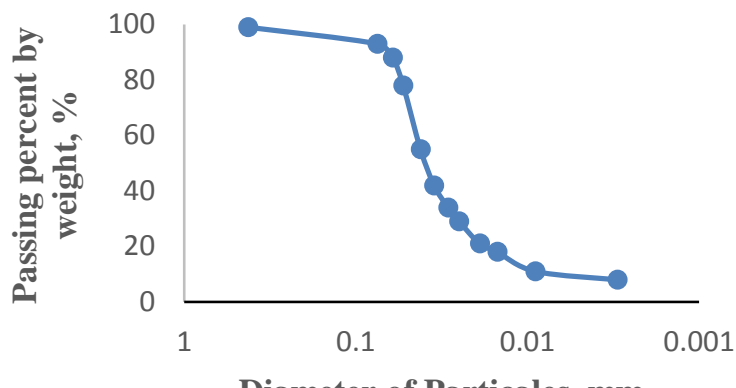

Fig. 1: Grain size distribution curve of tested soil

\subsubsection{Specific gravity}

The specific gravity of the selected soil in this study was determined according to test for specific gravity of soils (AASHTO T-100); the temperature effect was considered. The average of triplicate samples was adopted as the specific gravity value for the tested soil was 2.76 .

\subsubsection{Atterberg limits}

The liquid limit (LL) and plastic limit (PL) of the soil used were determined based on standard tests presented by AASHTO T-89 and AASHTO T-90 to be $41 \%$ and $25 \%$ respectively. Based on these values, the toughness index was calculated to be 2 . The grain size distribution and Atterberg limits exhibited that the soil has activity value equal to $1.3(>1.25)$ [27].

\subsubsection{Classification of soil}

The soil was classified according standard practice for classification of soils and soil-aggregate mixtures for highway construction purposes (ASTM D-3282). Based on grain size distribution, more than $99 \%$ of the particles are finer than $75 \mu \mathrm{m}$. This value $(99 \%)$ is higher than $36 \%$ which restrict the group of the soil between A-4, A-5, A6, and A-7. The values of Atterberg limits ( $\mathrm{LL}=41 \%$ and $\mathrm{PL}=$ $25 \%$ ) refer that the group of the soil is A-7. The plasticity index PI (LL-PL) was found to be $16 \%$ which is more than (LL -30); this result put the soil in the subgroup A-7-6 (silt-clay material) that rated as fair to poor subgrade.

\subsubsection{Moisture density relationship}

Modified Proctor compaction test was performed according to AASHTO T-180 to establish the relationship between water content and the dry density of the soil as shown in Figure 2. The optimum water content and maximum dry density were found to be $14.6 \%$ and $1890 \mathrm{~kg} / \mathrm{m} 3$ respectively.

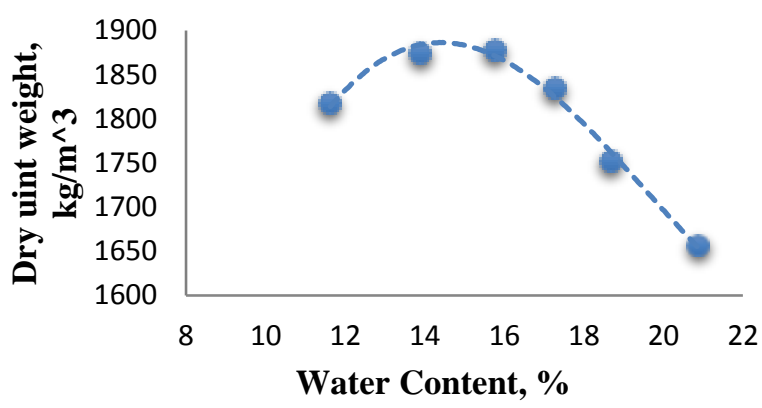

Fig. 2: The moisture-dry unit weights relationship of soil used

\subsection{Magnesium Oxide}

$\mathrm{MgO}$ was purchased from a specialized company (the Central Drug House (P) Ltd). The main physical and chemical properties of $\mathrm{MgO}$ used in this study were obtained from the manufacture manual as presented in Table 1 .

Table 1: Physical properties and chemical analysis results of $\mathrm{MgO}$

\begin{tabular}{lc}
\hline \multicolumn{1}{c}{ Physical Properties } \\
\hline Colure & White \\
Shape & Amorphous \\
Purity & $99.64 \%$ \\
Solubility in dilute acid & $97-100 \%$ \\
Filling volume (min) & $100 \mathrm{ml} \mathrm{/15} \mathrm{gm}$ \\
Loss on ignition (at 900 C) & $9 \%$ \\
Substances insoluble in acetic acid & $0.1 \%$ \\
Substances insoluble in hydrochloric acid & $0.1 \%$ \\
\hline \multicolumn{2}{c}{ Chemical Compounds } \\
\hline Free alkali and water soluble substances & $2 \%$ \\
Chloride (Cl) & $0.15 \%$ \\
Sulphate and Sulphate (as SO $\mathrm{S}_{4}$ ) & $0.5 \%$ \\
Arsenic (As) & $0.0004 \%$ \\
Calcium (Ca) & $1 \%$ \\
Iron & $0.05 \%$ \\
Heavy metals (as Pb) & $0.002 \%$ \\
\hline
\end{tabular}

\subsection{CBR Test}

A series of tests were performed using CBR method (AASHTO T193) on a number of samples prepared at the optimum moisture content and compacted with energy of $2,700 \mathrm{kN}-\mathrm{m} / \mathrm{m} 3$. To prepare for testing, one control sample and six samples enhanced with different doses of $\mathrm{MgO}(0.25 \%, 0.5 \%, 0.75 \%, 1 \%, 1.25 \%$, and $1.5 \%$ by the dry weight of the selected soil) were prepared. The samples were left for curing for three days which is a practical and effective period [28] at controlled temperature (around 25oC) and relative humidity about $60 \%$ as measured by digital psychrometer. Afterword, the samples were soaked in water for 96 hours. Thereafter, the final swelling was recorded and the samples were tested by CBR penetration loading machine. The readings were recorded to calculate the CBR values for each sample.

\subsection{Cyclic Triaxial Compression Test}

A series of cyclic triaxial compression tests were performed according to AASHTO T-307 on a number of control and enhanced samples prepared under conditions as same as those adopted in CBR test. This test is adopted to determine the values of resilient modulus (Mr) of subgrade soils. Mr is the capability of subgrade to recover strain under repeated loads. This test involved 15 sequences; each includes 3 confining pressures.

\section{Results and discussion}

Based on laboratory investigations described in the previous sections, a number of results were obtained. The soil can be classified 
as (A-7-6) with toughness index of 2 and high activity; these results refer to poor subgrade according to ASTM D-3282.

As mentioned previously, CBR test method was adopted to investigate the effect of different doses of $\mathrm{MgO}$ on the properties of s selected subgrade soil in this study. Results exhibited that the CBR values for the samples enhanced with $\mathrm{MgO}$ are higher than that for control soil. Figure 3 shows that the value of CBR for control soil is $(3.39 \%)$ whereas $\mathrm{CBR}$ values for soil enhanced with $\mathrm{MgO}$ doses of $(0.25 \%, 0.5 \%, 0.75 \%, 1 \%, 1.25 \%$, and 1.5$)$ are $(13.59 \%, 18.45 \%$, $27.54 \%, 25.24 \%, 16.99 \%$, and $14.56 \%$ ) respectively. Although all CBR values of enhanced soil are higher than that of control soil, there is a specific trend in improving of CBR as illustrated in Figure 3. However, the highest CBR value can be obtained from treated soil with $0.75 \%$ of $\mathrm{MgO}$ which refers to optimum dose. The values of CBR obtained from treated soil with doses less or more than $0.75 \%$ are less. This trend can be justified by increasing in the strength of enhanced soil due to chemical bond which produced by reaction of $\mathrm{MgO}$ with components of the soil; increasing of the dose increases the bond leading to increase in strength and consequently increase in $\mathrm{CBR}$ values. However, excess $\mathrm{MgO}$ (more than the optimum dose) decreases the density as the volume of chemical reaction product is higher than the volume of the reacted materials (soil components and $\mathrm{MgO}$ ). The reduction of soil density after curing leads to reduction in strength as the soil density is an indicator of strength. To validate this justification, the density of the samples (control and enhanced samples) were determined after soaking according to ASTM D-2637. The results are shown in Figure 4.

The CBR value of soil enhanced with $0.75 \% \mathrm{MgO}$ represents about $810 \%(27.54 / 3.39 \times 100 \%)$ of that for control soil. This value refers to a significant improvement in subgrade strength.

CBR tests implemented in this study covered the determination of swelling ratios for the control and enhanced samples. The results exhibited that the swelling ratios decrease in samples enhanced with $\mathrm{MgO}$ compared with that of control samples. Figure 5 shows that the swelling ratio for control sample is (3.4\%) whereas swelling ratios of samples enhanced with $\mathrm{MgO}$ doses of $(0.25 \%, 0.5 \%, 0.75 \%$, $1 \%, 1.25 \%$, and 1.5 by the dry weight of the selected soil) are $(1.51 \%, 0.80 \%, 0.61 \%, 0.66 \%, 1.18 \%$, and $1.97 \%)$ respectively. In addition to the findings that all swelling ratios of enhanced soil are lower than that of control soil, there is a specific trend in decreasing as illustrated in Figure 5. However, the lowest swelling ratio can be obtained by treatment of soil with $0.75 \%$ of $\mathrm{MgO}$ which refers to the optimum dose. The justification of this trend is similar to that described in case of CBR trend as the swelling is a function of volume change and bond among soil particles. The swelling ratio of the enhanced soil with $0.75 \% \mathrm{MgO}$ represents about $17 \%$ of that for control soil. This value refers to significant decrease in swelling susceptibility and consequently significant improvement in subgrade properties.

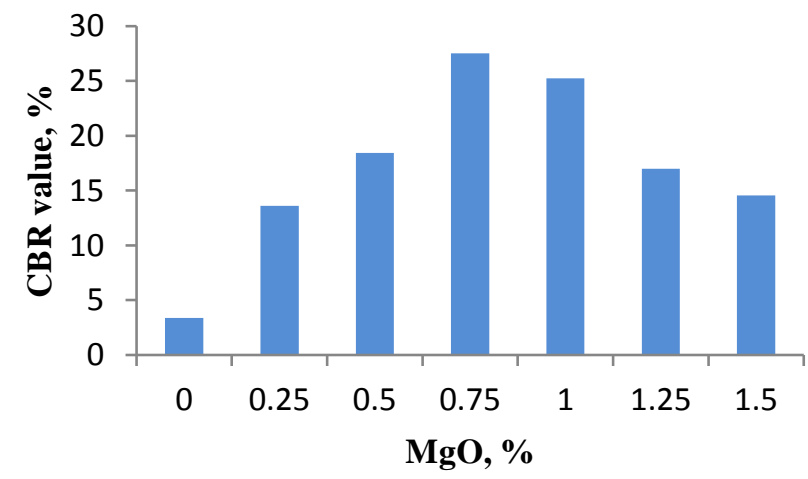

Fig. 3: $\mathrm{CBR}$ values for samples with different doses of $\mathrm{MgO}$

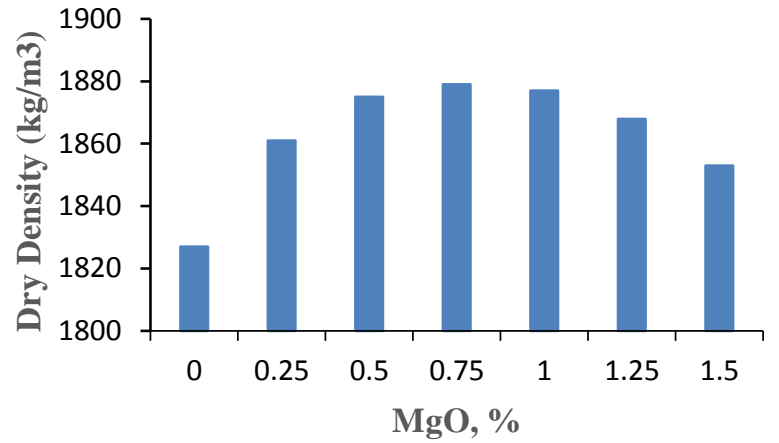

Fig. 4: Density values for samples after soaking with different doses of $\mathrm{MgO}$

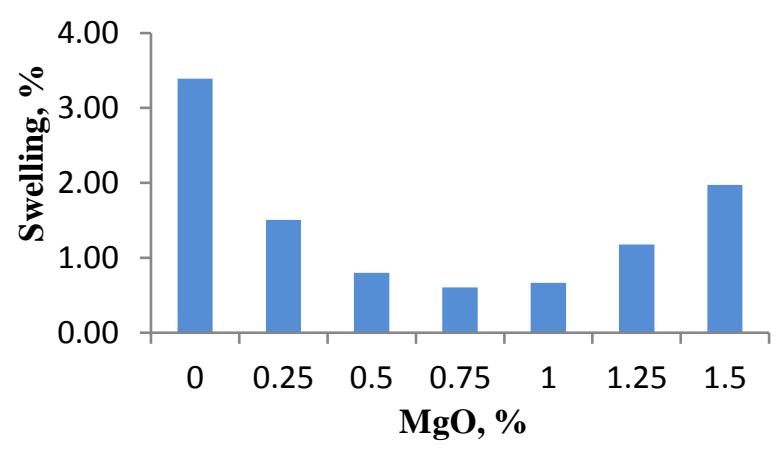

Fig. 5: Swelling ratios for samples with different doses of $\mathrm{MgO}$

Cyclic triaxial compression tests results exhibited that $\mathrm{Mr}$ of control soil is $35 \mathrm{MPa}$ whereas $\mathrm{Mr}$ values of samples enhanced with $\mathrm{MgO}$ doses of $(0.25 \%, 0.5 \%, 0.75 \%, 1 \%, 1.25 \%$, and 1.5$)$ are $(83,97,150$, 137,110 and $103 \mathrm{MPa}$ ) respectively as shown in Figure 6 . The highest $\mathrm{Mr}$ value was obtained by adding $0.75 \%$ of $\mathrm{MgO}$ (the optimum dose). As shown in Figure 6, Mr values follow a trend similar to that of CBR values. The justification of this trend is similar to that described in case of CBR trend. Mr value of soil enhanced with $0.75 \% \mathrm{MgO}$ represents about $428 \%$ of that for control soil. This value refers to a significant increase in subgrade capability to carry heavy traffic loading.

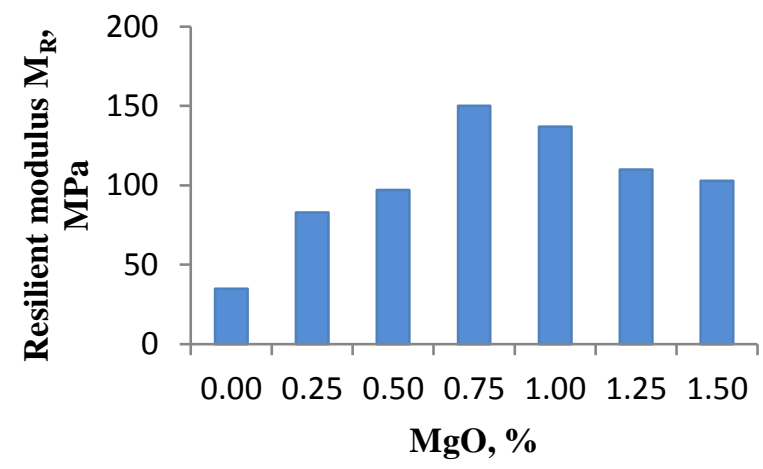

Fig 6: Resilient modulus for samples with different doses of $\mathrm{MgO}$

\section{Conclusions}

This study is a laboratory-oriented approach to investigate the effects of $\mathrm{MgO}$ addition on subgrade properties. The results of the study exhibited that adding $\mathrm{MgO}$ for soft clay soils used as a subgrade improves its properties in terms of increase in CBR values and decrease in swelling ratio values. A number of conclusions can be abstracted in the following points:

1. Compared with control samples, samples enhanced with $\mathrm{MgO}$ doses of $(0.25 \%, 0.5 \%, 0.75 \%, 1 \%, 1.25 \%$, and $1.5 \%)$ exhibited increase in CBR values to $(400 \%, 543 \%$, $810 \%, 743 \%, 500 \%$, and $429 \%$ ) respectively 
2. Compared with control samples, samples enhanced with $\mathrm{MgO}$ doses of $(0.25 \%, 0.5 \%, 0.75 \%, 1 \%, 1.25 \%$, and $1.5 \%)$ exhibited decease in the swelling ratios to $(45 \%$, $24 \%, 17 \%, 20 \%, 35 \%$, and $58 \%$ ) respectively.

3. Samples enhanced with $\mathrm{MgO}$ doses of $(0.25 \%, 0.5 \%$, $0.75 \%, 1 \%, 1.25 \%$, and $1.5 \%$ ) exhibited increase in $\mathrm{Mr}$ values to $(237 \%, 277 \%, 428 \%, 391 \%, 314 \%$, and $294 \%)$ respectively compared with that of control one.

4. The optimum dose that yields the highest CBR and $\mathrm{Mr}$ values and the lowest swelling ratio is $0.75 \%$.

5. These results refer to a significant improvement in subgrade properties. This improvement leads to a significant increase in subgrade ability to withstand the repetitive traffic loading. As a result, the thickness of the pavements layers can be reduced without affecting the capacity of the layered system of pavements to carry traffic load. This reduction, considerably, reduces the initial cost of pavements construction.

6. Improvement of subgrade properties increases the design period and eliminates the probable damages in pavements which reduces the maintenance costs and increases the serviceability.

\section{References}

[1] Mosa AM, Taha MR, Ismail A, Rahmat RAOK, “ A Diagnostic Expert System to Overcome Construction Problems in Rigid Highway Pavement", Journal of Civil Engineering and Management. Vol.19, (2013), pp.846-861.

[2] Mosa AM, Rahmat RAOK, Ismail A, Taha MR, "Expert System to Control Construction Problems in Flexible Pavements", Computer Aided Civil and Infrastructure Engineering. Vol. 28, (2013), pp.307323.

[3] Mosa AM, Atiq R, Raihantaha M, Ismail A, "A Knowledge Base System to Control Construction Problems in Rigid Highway Pavements". Australian Journal of Basic and Applied Sciences. Vol.5, (2011), pp.1126-1136.

[4] Mosa AM, Atiq R, Raihantaha M, Ismail A. "Classification Of Construction Problems in Rigid Highway Pavements". Australian Jour nal of Basic and Applied Sciences. Vol.5, (2011), pp.378-395.

[5] Mosa AM. "Neural Network for Flexible Pavements Maintenance and Rehabilitation". Applied Research Journal. Vol.3, (2017), pp.114-129.

[6] Mosa AM, Ismail NN, Yusoff NIM, Mubaraki MA, Memon NA, Taha MR, et al., "An Expert System to Remedy Concrete Imperfections and Their Effects On Rigid Pavements". Jurnal Teknologi. Vol.76, (2015), pp.105-119.

[7] Mosa AM, Taha MR, Ismail A, Rahmat RAOK. "An Educational Knowledge-based System For Civil Engineering Students in Cement Concrete Construction Problems". Procedia - Social and Behavioral Sciences. Vol.102, (2013), pp.311-319.

[8] Mosa AM, Taher AH, Al-Jaberi LA. "Improvement of poor subgrade soils using cement kiln dust". Case Studies in Construction Materials. Vol.7, (2017), pp.138-143.

[9] Mosa AM, Banyhussan QS, Yousif RA. "Improvement of expansive soil properties used in earthworks of highways and railroads using cement kiln dust". Journal of Advanced Civil Engineering Practice and Research. Vol.4, (2017), pp.13-24.

[10] Mosa AM. "Modification of Subgrade Properties Using Waste Material”. Applied Research Journal. Vol.3, (2017), pp.160-166.

[11] Karpushko EN, Bartolomei IL, Karpushko MO. "Study of Using the Possibility of Textile Sand Piles at the Base of the Automobile Road Folded by Saline Soils". Procedia Engineering. Vol.150, (2016), pp.2287-2292.

[12] Bozbey I, Demir B, Komut M, Saglik A, Comez S, Mert A. "Importance of Soil Pulverization Level in Lime Stabilized Soil Performance". Procedia Engineering. Vol.143, (2016), pp.642-649.

[13] Ranadive MS, Tapase AB. "Parameter sensitive analysis of flexible pavement". International Journal of Pavement Research and Technology. Vol.9, (2016), pp.466-472.

[14] Mosa AM. "Modification of Hot Mix Asphalt Using Polyethylene Therephthalate (PET) Waste Bottles". SUST Journal of Engineering and Computer Sciences. Vol.18, (2017), pp.62-73.

[15] Gomes Correia A, Winter MG, Puppala AJ. "A review of sustainable approaches in transport infrastructure geotechnics". Transportation Geotechnics. Vol.7, (2016), pp.21-28.
[16] Venmans AAM, van de Ven R, Kollen J. "Rapid and Non-intrusive Measurements of Moisture in Road Constructions Using Passive Microwave Radiometry and GPR - Full Scale Test". Procedia Engineering. Vol.143, (2016), pp.1244-1251.

[17] Ozdemir MA. "Improvement in Bearing Capacity of a Soft Soil by Addition of Fly Ash". Procedia Engineering. Vol. 143, (2016), pp.498-505.

[18] Puppala AJ. "Advances in ground modification with chemical additives: From theory to practice". Transportation Geotechnics. Vol.9, (2016), pp.123-138.

[19] Heitor A, Indraratna B, Rujikiatkamjorn C. "Small Strain Behaviour of a Compacted Subgrade Soil". Procedia Engineering. Vol.143, (2016), pp.260-267.

[20] Silvani C, Braun E, Masuero GB, Consoli NC. "Behavior of SoilFly Ash-Lime Blends Under Different Curing Temperatures". Procedia Engineering. Vol.143, (2016), pp.220-228.

[21] Uzer AU. "Use of Biofuel Co-Product For Pavement Geo-Materials Stabilization". Procedia Engineering. Vol.125, (2015), pp.685-691.

[22] Huang K, Deng M, Mo L, Wang Y. "Early Age Stability of Concrete Pavement by Using Hybrid Fiber Together With Mgo Expansion Agent In High Altitude Locality". Construction and Building Materials. Vol.48, (2013), pp.685-690.

[23] Gao P-w, Xu S-y, Chen X, Li J, Lu X-1. "Research On Autogenous Volume Deformation of Concrete with Mgo". Construction and Building Materials. Vol.40, (2013), pp.998-1001.

[24] Zhang T, Cheeseman CR, Vandeperre LJ. "Development of Low Ph Cement Systems Forming Magnesium Silicate Hydrate (M-S-H)". Cement and Concrete Research. Vol.41, (2011) pp.439-442.

[25] Peiwei G, Xiaolin L, Shaochun J, Hui Z, Chunxing G. "Using A New Composite Expansive Material to Decrease Deformation and Fracture of Concrete". Materials Letters. Vol.62, (2008), pp.106-108.

[26] Gao P-w, Wu S-x, Lu X-1, Deng M, Lin P-h, Wu Z-r, et al. "Soundness Evaluation of Concrete With Mgo". Construction and Building Materials. Vol.21, (2007), pp.132-138.

[27] Das, Braja M. "Advanced soil mechanics", CRC Press, (2013).

[28] Huang, Kaijian, Deng, Min, Mo, Liwu, Wang, Yuangang. "Early Age Stability of Concrete Pavement by Using Hybrid Fiber Together With Mgo Expansion Agent In High Altitude Locality". Construction and Building Materials. Vol.48, (2013), pp.685-690. 